Periodica Polytechnica Architecture, 51(2), pp. 149-164, 2020

\title{
Exploring Knowledge Workers in the Turkish Construction Sector
}

\author{
Atacan Akgün ${ }^{1 *}$, Hakan Yaman² \\ ${ }^{1}$ Department of Architecture, Faculty of Architecture, Erciyes University, 104 Ahmet El Biruni Street, 38039 Kayseri, Turkey \\ 2 Department of Architecture, Faculty of Architecture, Istanbul Technical University, 2 Taşkışla Street, 34367 Şişli, Istanbul, Turkey \\ * Corresponding author, e-mail: atacan@erciyes.edu.tr
}

Received: 24 March 2020, Accepted: 05 October 2020, Published online: 05 November 2020

\section{Abstract}

This research focuses on evaluating the potential of architects/engineers as Knowledge Workers (KW) operating in the Turkish construction sector. A survey to identify the presence of KWs was prepared and applied to 113 of 324 employees, including architects and engineers from 138 different large-scale Turkish contractor companies (head offices, design offices, technical offices and construction sites). The survey consists of two main sections that (1) recognise the profile of the participants and companies and (2) six sub-sections as communication, motivation, autonomy, possessing theoretical and practical knowledge, ability to access and use information, and intellectual ability. The results of the survey indicate that architects have a higher potential to be identified as KWs than engineers in the Turkish construction sector. Furthermore, the number of KWs among the design and head office workers is higher, because there are a higher number of architects working in these departments.

The potential of being a KW increases in parallel to the level of education of the employees, which is determined from a Bachelor's degree and PhD degree. When examining gender statistics in the survey, women employees have higher scores than men. The findings of this study should guide the construction sector professionals in Turkey as well as those from other countries who seek to identify the KWs in the contractor companies. This research, with the approach and methodology, may provide better management of human resources by identifying and placing these valuable employees correctly.
\end{abstract}

\section{Keywords}

Knowledge Worker (KW), construction, Turkey

\section{Introduction}

Significant and radical changes have taken place in building production organisations, especially in the last century. The understanding of construction management has also had to change due to changing economic, technological and social conditions in the world. The increasing customer expectations, globalisation of the construction economy, the challenging and competitive environment of the construction sector and tight profit margins compel the sector to this change (The Boston Consulting Group, 2016). Besides this, the sector has had to deal with issues such as the decomposition of design and construction, fragmented production methods, hostile relations and the reluctance to develop and use information technologies. The construction sector is in a difficult situation due to poor and unstructured training processes, management and implementation systems that require intensive procedures and in-house communication problems. The problems in the generation, control and sharing of knowledge, which has become the crucial component of the different phases of projects together with the increasing momentum of development, prevent the ideal conditions for obtaining high-quality products to a targeted budget and on time.

In summary, traditional project life cycle processes have difficulty in responding to present-day realities. A more efficient approach for responding to these issues could be an updateable system-planning concept that is based on the employees at the centre of "the knowledge". One of the most significant problems faced by construction companies is to manage their intellectual capital (Kululanga and McCaffer, 2001). Companies' strong ties with knowledge provide a sustainable advantage in the competitive environment of the construction industry (Issa and Haddad, 2008). In this context, it is inevitable that KWs, who can produce, use, transfer and save and share information, are evaluated in accordance with their potential in the construction sector. The most practical and healthiest way to preserve "knowledge" is to preserve the "source 
of knowledge". Thus, it is crucial to identify the "sources" correctly. This paper explains the results and evaluations of the survey applied to employees in large-scale contractors operating in the Turkish construction sector to identify architects/engineers as the potential KWs.

To conclude, this study aims to determine the KWs in large-scale contractors in the Turkish construction sector through a survey based on the specified characteristics of KWs. The results of this survey reveal the presence of KWs in the Turkish construction sector. Considering the construction projects conducted with limited sources and the rigid and bulky organisation structures of the present construction companies, the determination of the KWs who believe that he/she is not in the position that they deserve in the hierarchy is critical. It is imperative to identify personnel who know what to do with knowledge in the construction industry, where knowledge is one of the essential components. Consequently, this study is considered an important beginning for the evaluation of KWs according to their capabilities and potentials specific to the construction sector in Turkey.

\section{Literature review}

Different approaches define Knowledge Workers and their characteristics with varying perspectives. Thus, a comprehensive literature research was conducted to examine and clarify the definition of KW and their primary specifications to create the basis of this research. The survey is prepared utilising the definitions and characteristics of KWs in the literature, with KWs in the Turkish construction sector evaluated in the context of these characteristics.

\subsection{Definition of Knowledge Workers in history}

The concept of "Knowledge Worker" was first mentioned in 1959 by Drucker, who was one of the most influential management theoreticians of recent history. Drucker (1959) defines KWs as senior employees who use theoretical and analytical knowledge acquired through formal education to develop products and services. He also states that the employee profile would be the most valuable asset of the 21st-century business environment due to their level of productivity and creativity. Fritz Machlup (1962), the economist, describes exclusive employees as a new type of employee who is responsible for the entire range of activities, from the carrier of knowledge to the original creator. Machlup unambiguously identifies KWs with this definition. After Drucker introduces the concept of KW (Drucker, 1959), many scholars and theoreticians describe KWs from different perspectives. Yang et al. (2002) emphasise that a KW is an employee who engages in knowledge work. Thomas Davenport (2005) defines KW as the employee whose capital is knowledge and thinking for a living. This definition supports and summarises the previous definitions and approaches the concept of KW in literature.

Nevertheless, the existence of the concept of KW dates to an older period than its definition. This phenomenon, which emerged with the existence of humanity, has only recently found its place in the literature. The $\mathrm{KW}$, who rises in value with the information age, is the anonymous hero of the progression. In this study, KWs are defined as the employees who generate the knowledge, use the knowledge efficiently to create "value", store, transfer and share the knowledge as their primary and peculiar skills.

\subsection{Characteristics of Knowledge Workers}

There are different definitions regarding a KW, and these varying approaches can be noticed in the classifications of KWs. Given the definitions of KWs in the literature, there is a logical integrity observed among them. However, this logical integrity cannot be determined in defining the characteristic features of the KWs. When the previous research regarding the productivity of KWs is examined, the results vary according to the characteristics. According to Drucker (1999b), the productivity of a KW is determined by six major factors: being task-oriented, autonomy, innovation, continuous learning and teaching, being quality-oriented, being value-centred. Morgeson and Humphrey (2006) propose five characteristics of KWs: job complexity, information processing, problem-solving, skill variety, and specialisation. Mohanta et al. (2006) propose six characteristics of KWs: possessing factual and theoretical knowledge, finding and accessing information, ability to apply information, communication skills, motivation and intellectual abilities. Cochran and Ferrari (2009) identify the skills for success in the knowledge economy as follows: thinking skills, communication, teamwork and leadership, continuous learning and self-direction, technology adoption and application, professionalism and ethics. The research conducted by Zhan et al. (2013) posits 35 characteristics of KWs by using the common features concluded in more than 10 studies. These characteristics are independence, high level of turnover, creativity, being challenging to supervise the work processes, realising self-value, being difficult to measure the work results, knowledge capital, dimly bounds of leadership and being 
contemptuous of the authority, being loyal to the occupations instead of employers, individual characters (Zhan et al., 2013). The common characteristics of KWs concluded from the literature are classified in this study as communication, motivation, autonomy, possessing theoretical and practical knowledge, ability to access and use information, and intellectual ability.

In reality, the modern workplace is a complex environment of human actions with a varied set of tasks and responsibilities. Furthermore, effective and efficient communication is one of the crucial factors in taking responsibility in working environments. Additionally, today's enterprises "are no longer built on force but trust", so people must understand each other (Drucker, 2005). Specifically, transferring information from one to another is a significant factor affecting the completion of construction projects successfully (Giritli et al., 2010). According to Dainty et al. (2006), effective communication is essential in the successful delivery of construction projects. In this context, effective communication is an essential topic for the modern business environment in which KWs are very active.

One of the principal prerequisites for a KW to be successful is high motivation. The driving force that a KW needs to develop themself is the motivation for their work. There is a consensus in the literature that KWs are professionals who are highly motivated to perform well (Davenport, 2005; Drucker, 1954; Reboul et al., 2006). Thus, motivation is a significant factor in the evaluation of KWs.

According to Drucker (1967), KWs cannot be supervised strictly; they decide what, when or how to do and only except indirect support. Also, McGovern (1999) highlights that KWs present as independent-minded characters. Davenport (2005) emphasises that KWs enjoy autonomy in their work and like to be independent. Therefore, autonomy is determined as a crucial feature of KWs.

Davenport (2005) emphasises that KWs are knowledge producers who utilise experience, innovation, creativity, and the transformation of experience into knowledge to leverage products and services. Furthermore, KWs should be innovative to respond to the need for "continuous learning on the part of the knowledge worker" (Drucker, 1985; 1999a). An employee who is considered as a "knowledge producer" and "continuous learner"refers to the KW who possesses theoretical and practical knowledge. In addition, Davenport (2007) underlines that KWs can produce, share and use information and knowledge under any conditions independent of time and place. Taking Davenport's and Drucker's studies into consideration, KWs' ability to access and use information is revealed.

Drucker (1999a) argues that KWs can define what the task is or how it should be done on their own in contrast to manual workers. This definition clearly emphasises the intellectual ability of KWs. Eisenhardt and Santos (2006) underline that attracting smart and talented employees and raising their intellectual abilities level will be the new millennium's competence.

\subsection{Knowledge Workers in the construction sector}

The construction sector has a competitive character due to its large economy. The stakeholders of this sector face many difficulties related to performance issues. Today, construction professionals emphasise the importance of using all kinds of information more effectively in the construction industry. This potentially gives them a competitive advantage (Carrillo et al., 2000). That people are the most valuable asset for a company is primarily observed in labour-intensive industries, and especially in the construction industry (Green et al., 2004). There are many knowledge-oriented services in the background of the building production organisation such as design, procurement, implementation, surveying, controlling and management (den Hertog and Bilderbeek, 1998). The performance and innovation level required by the construction industry can only be achieved through an effective knowledge management strategy since the focus of companies has shifted from asset to knowledge (Kamara et al., 2003; Webb, 1998).

One of the most critical issues to be considered about knowledge management in the construction industry is not ignoring people as they are the primary sources of knowledge. Thus, knowledge management in the construction industry is only possible with people/employees. The value given to the knowledge should also be given to the producer of the knowledge. In an industry where every product has a unique character such as construction, the problems encountered are mostly specific to the project (Carty, 1995). KWs have considerable responsibilities in the construction sector, where the end product is completed with limited resources (time, cost, labour). KWs who produce, use, share and store value-added information also could think quickly and effectively. Furthermore, they could be solution-oriented and have intellectual depth to carry out building production activities smoothly and solve the project-specific problems. However, to define this responsibility, the presence of KWs in the construction sector must first be determined. 
Green et al. (2004) state that the concept of KW in the construction industry has been considered as an important topic for a long time. In the literature, $\mathrm{KW}$ is generally addressed under the title of knowledge management. According to Rezgui, some crucial reasons limit present knowledge management approaches in the construction industry (Rezgui, 2001). These reasons result because critical knowledge is kept only in the mind of the employees who participate in the project. Unfortunately, the decisions taken during the construction process or the project-specific problems and their solutions are not recorded and documented regularly in many cases. Thus, valuable knowledge is lost when the employees who produced or experienced it leave the company. These limitations validate the direct link between the human factor in the construction industry and knowledge. In addition, they underline the concept of $\mathrm{KW}$, which has a central position in the performance of the construction industry (Pathirage et al., 2005). According to Sheehan et al. (2005), $80 \%$ of the useful knowledge that employees in the construction industry have is tacit and could not be recorded.

The systematisation of information management in the construction industry is studied by developing models on the systematisation and documentation of the tacit and open knowledge produced by the employees for the use of the contractors (Kivrak et al., 2008; Ozorhon et al., 2014). According to these models, most Turkish contractors do not have an implemented strategy for the systematic storage of knowledge. A similar study was conducted by architectural firms operating in Turkey (Ökten, 2016). Although there are research or models about knowledge management, there is no evidence about the application of these models in any construction firms in Turkey. Also, there is no study or research about the identification and placing of the employee who is considered as a source of knowledge.

On the other hand, Schröpfer et al. (2017) studied mapping the knowledge flow in sustainable construction project teams using the social network analysis method. In this research, the knowledge was followed through the sustainable projects and the results were interpreted. However, none of these projects can determine the KWs involved.

There are several academic studies regarding the classification and documentation of knowledge in the construction industry. However, no academic study or research involving a strategy to determine KWs who are the main resource of valuable knowledge has been identified. Also, the utilisation of employees who are trained in gathering and organising knowledge in the company is considered as a problem to be solved. Thus, it is concluded that identifying the KW trapped in the hierarchical confusion in the construction sector has yet to be investigated. The construction industry benefits from the skilled, unskilled and managerial people from different disciplines (Loosemore et al., 2003). Determining a KW among all these people is critical for knowledge management in the construction sector.

In the process of evolving the construction sector from a labour-intensive character to a knowledge-intensive character, it is vital to work on keeping the KWs within the company. To achieve this goal, this type of employee should first be identified as KWs are the resources for the transformation of the construction sector according to the needs of the developing contemporary organisation models in construction. Thus, determination and utilisation of KWs in construction companies are crucial to increase the efficiency, produce and maintain the knowledge in a systematic organisation model and transform the experience and knowledge of the employee into the assets of the company. This study pioneers a methodology and model for the definition and determination of KWs in the Turkish construction sector. The basis of this research was concluded from a comprehensive literature survey and interpreted according to the dynamics of the construction sector. The structure of the survey is intended to serve as a backbone to the research. The methodology and results of this research are expected to be reproduced in the companies in the Turkish construction sector whose concerns are the determination and utilisation of KWs for more efficient working and production environment.

\section{Research methodology}

Section 3 describes the research process and methodology of this study. The objectives and scope were determined. The survey was prepared to acquire the data, and a pilot test was applied to check the efficiency and consistency of the survey. Finally, the survey was applied to 113 participants, and the data was analysed and interpreted (Fig. 1).

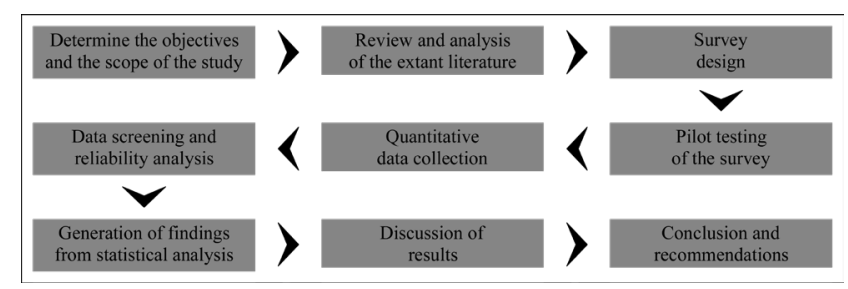

Fig. 1 Methodological flow chart for the study 


\subsection{Survey design}

To have consistent results, architects and engineers who are directly related to the construction works, have comprehensive job descriptions, and have a high level of education are selected as participants. Some 245 architects and engineers were contacted from 138 different largescale Turkish contractor companies for the survey. It is thought that the participants who understand the main idea of the study are present only in large-scale construction companies that pay attention to the selection of qualified personnel. Therefore, the Turkish Contractors Association (TMB) and The Association of Real Estate Investment Company (GYODER) membership of the companies have been determined as a prerequisite for being a part of this research. The survey was online between 11 September 2019 - 15 October 2019 by Google Forms. Architects/ engineers answered from different age groups with different experience and workload capacities from a variety of cities in Turkey. From 57 companies, 113 participants responded to the survey. The response rate is $46 \%$.

\subsection{Instruments}

A quantitative approach was used to solicit the views of experts within the Turkish construction sector on the issue under investigation. The close-ended survey was used to obtain the data. The survey comprises two subsections where 112 questions were asked under these sections. Subsection 4.1 sought the demographic information of the participants. It covers the demographic questions and gathers information related to the participants' gender, age, educational background, occupation, and work experience. The Subsection 4.2 sought the views of the participants on identifying KWs in the Turkish construction sector. The Subsection 4.2 consists of six sub-subsections. These sub-subsections are defined according to the characteristics of the KW, which were determined as communication, motivation, autonomy, possessing theoretical and practical knowledge, ability to access and use information, and intellectual ability. The questions in the Subsection 4.2 were prepared based on the Expert Review Questionnaire in Wong's (2012) work and Knowledge Work Productivity Assessment (KWPA) Questionnaire in Antikainen and Lönnqvist's (2005) work. Wong (2012) tried to measure the productivity of KWs on organisational, departmental and individual levels. Antikainen and Lönnqvist (2005) tried to measure the productivity of knowledge work under the titles of the organisational input factors, personal factors, process-related factors and output factors. To design a survey in the context of this paper, the questions from Wong (2012), and Antikainen and Lönnqvist (2005) were updated. These were developed according to the six sub-subsections and are based on the characteristics of KWs. The survey questions are based on these studies since there is no direct study on the characteristics of KWs or the productivity of KWs, referring to the characteristics of KWs.

All the questions from the Subsection 4.2 of the survey have been designed using a 5-points Likert scale. The purpose of using a Likert question is to symbolise different directions of the same manner. Five points within the scale have been chosen since they give enough discrimination for most purposes and can easily be understood by the participants (Brace, 2004). The participants' score on a Likert scale of 1 to 5 is defined as strongly disagree, disagree, undecided, agree, and strongly agree.

\subsection{Data analysis}

The data collected using the survey were analysed and assessed by using Microsoft Excel ${ }^{\mathrm{TM}}$. The correlations were calculated by using the statistics program (TURCOSA) and the significance level ( $p$-value) in the study was determined as 0.05 . $P$-value indicates the error margin when "there is a statistically significant difference" decision is needed in a comparative study. Fisher proposes the maximum acceptable level of this error margin as 0.05 , which is agreed in the literature (Fisher, 1925). In addition, a correlation matrix was created in terms of correlation coefficient ( $r$-value). The results are presented in the Section 4.

\section{Results and discussion}

Cronbach's alpha value, which is the most popular reliability statistic to prove the consistency of the survey, is calculated. The Cronbach alpha value was determined as 0.87 (Cronbach, 1951) for the whole survey. As a rule of thumb, if $\alpha \geq 0.8$, then the answers are accepted as reliable (Carlbring et al., 2007). Therefore, internal consistency is considered good. Then, the gathered data in the survey are evaluated and interpreted on two different scales. The first one is the evaluation of the demographic data and educational background, positions and experience of the participants as general conclusions of the survey. Then, the second one focuses on the correlation matrix of KW characteristics, which also constitute the Subsection 4.2 prepared according to the Likert scale. Afterwards, the relation between the mean scores of demographic variables and general mean scores of KW characteristics determine the potential of the employee as a KW. This part of the 
assessment is more detailed because the answers and their consistency with each other are compared and evaluated together with statistical data.

\subsection{Demographic findings}

Although there has been a noticeable change in the construction sector in recent years, it can be said that it is currently a male-dominated sector at $83.19 \%$ with 94 participants. Of the participants, $4.42 \%$ were born between 1946-1964 (Baby Boomers), 15.93 \% of them were born between 1965-1979 (X generation), and 79.65\% of participants were born between 1980-1999 (Y generation). $68.14 \%$ of the participants have a Bachelor of Science (BS) degree, $29.20 \%$ of them have a Master of Science
(M.Sc.) degree, and $2.66 \%$ have Philosophy of Doctorate (PhD) degree. Architects make up $38.94 \%$ of the participants, and $61.06 \%$ are engineers (Table 1 ).

When the participants' professional experience in total is examined, it is found that the $14.16 \%$ of them have $0-5$ years, $43.36 \%$ of them have $6-10$ years, $22.13 \%$ of them have $11-15$ years, $13.27 \%$ of them have $16-20$ years, and $7.08 \%$ of them have 21 years and above professional experience in total. When the participants' experience in the current firm is examined, it is found that the $56.64 \%$ of them have $0-5$ years, $30.97 \%$ of them have $6-10$ years, $7.96 \%$ of them have $11-15$ years, $2.66 \%$ of them have 16-20 years, and $1.77 \%$ of them have 21 years and above experience in their current firm (Table 1).

Table 1 Demographic data of the participants

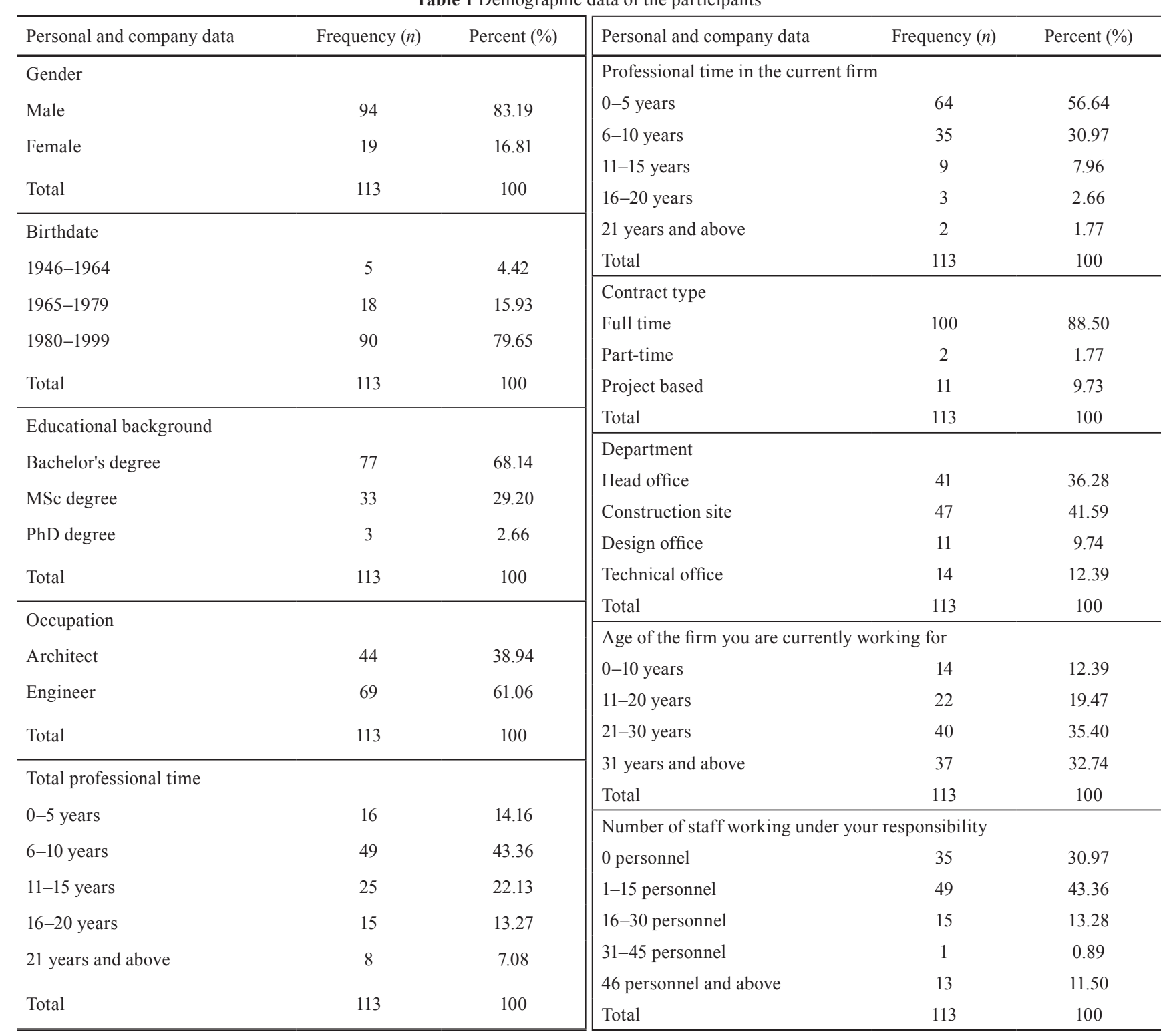


The following results were concluded according to the average demographic data gathered in the survey:

- The potential of female employees being a $\mathrm{KW}$ is higher than the male employees. This result in the construction sector, which is mostly dominated by male employers or employees can be interpreted as one of the remarkable signs of the success of educated women; despite societal pressure to the contrary in many areas of daily life.

- The ages of the participants were asked according to the Baby Boomers, Generation X and Generation Y age ranges in the scope of this study. The results indicate that the participants from the Baby Boomers and Generation Y have the potential to be a KW. It is not unexpected that the awareness of the participants from Generation Y who were born in the period when the development momentum of technology has been increasing is higher than the others. This is because the participants from Generation Y have a strong connection with the increasingly widespread information technologies; the results indicating the potential of being a KW from the Baby Boomer group is remarkable. This group also referred to as the post-war generation, are considered as closed to change and distant to innovation. For these reasons, the results regarding Baby Boomers are notable. The participants from Generation $\mathrm{X}$ in the construction sector are far from being a KW, and this result supports the characteristics of this generation, which can be summarised as having a high tendency to appreciate experience, respect authority and being contented.

- The employees having a $\mathrm{PhD}$ degree have a higher potential to be a KW in the context of the level of education. Similarly, the employees having a master's degree have a higher potential to be a KW than the employees who do not have a graduate degree. These results reveal that the level of knowledge and the status of being a KW worker is directly related.

- The results indicate that architects participating in the survey have higher averages than engineers and also have the potential to be identified as a KW. The dynamics of architectural production as ideas or applications demand an interdisciplinary working environment. However, engineers can be considered as the temporary and individual partners of the interdisciplinary architectural environment. Thus, claiming that architects have a higher tendency to be a KW than engineers in the construction sector due to the nature of the production of knowledge in these professions. Furthermore, architects have the responsibility to coordinate this interdisciplinary working environment, which supports their role as KW in the construction sector.

- The evaluation of the results, related to the total professional experience, could not specify a specific group coming to the fore. However, the participants with experience between $0-5$ years and $11-15$ years are generally above average. This confirms the results regarding Generation Y participants.

- Head office employees have the potential to be identified as a KW as a result of the evaluations based on the departments where the participant work. This result supports the considerations about architects concluded from the evaluations of the professional groups. Similarly, above-average results of design office workers confirm the considerations related to architects' being a KWs. Architects mostly work in the head office or design office in the contractor companies. Given that physical product develops on the construction site, KWs are expected to work on the construction sites. However, the results of the survey reveal the presence of KWs backstage of the construction sites.

The general mean scores of KW characteristics are highlighted yellow (Fig. 2). The mean scores of demographic variables above the general mean scores of KW characteristics are highlighted green. The answers given to each section in the survey are averaged, which then determines the section score. The minimum requirements to determine the $\mathrm{KW}$ in a working environment vary according to the level of competence of knowledge in the company where he/ she works. The requirements of being identified as KW of a worker with proactive, enthusiastic and promising employees and another worker without ambition, passive and low-profile employees cannot be the same. Therefore, the section-based averages of all participants were considered to address the general situation in this sector-wide study.

The characteristic features of KWs were evaluated within themselves. However, the relations of these sub-titles (correlation coefficient values) were also examined (Fig. 3). If the value is $0.2<r<0.4$, it indicates a weak positive relationship. If the value is $0.4<r<0.6$, it indicates a moderate positive relationship, and if the value is $0.6<r<0.8$, it indicates a strong positive relationship. It is seen that there are relationships between these subheadings, and the characteristics of KWs cannot be independent of each other. 


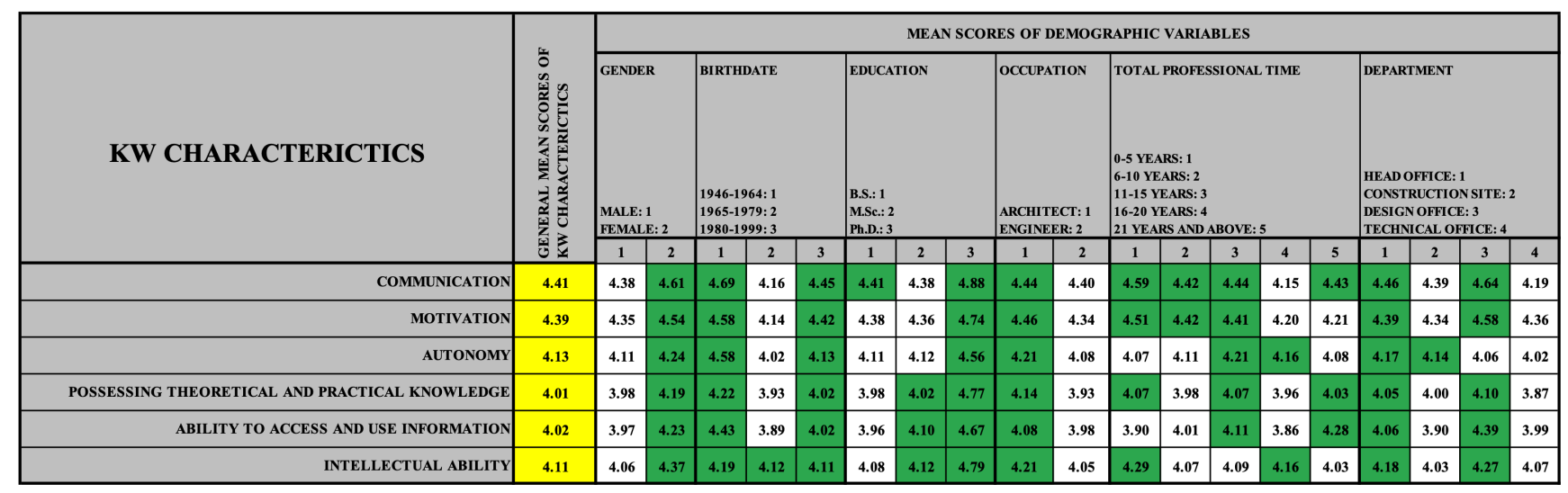

Fig. 2 Evaluation results of participants' demographic variables according to the general mean scores of KW characteristics

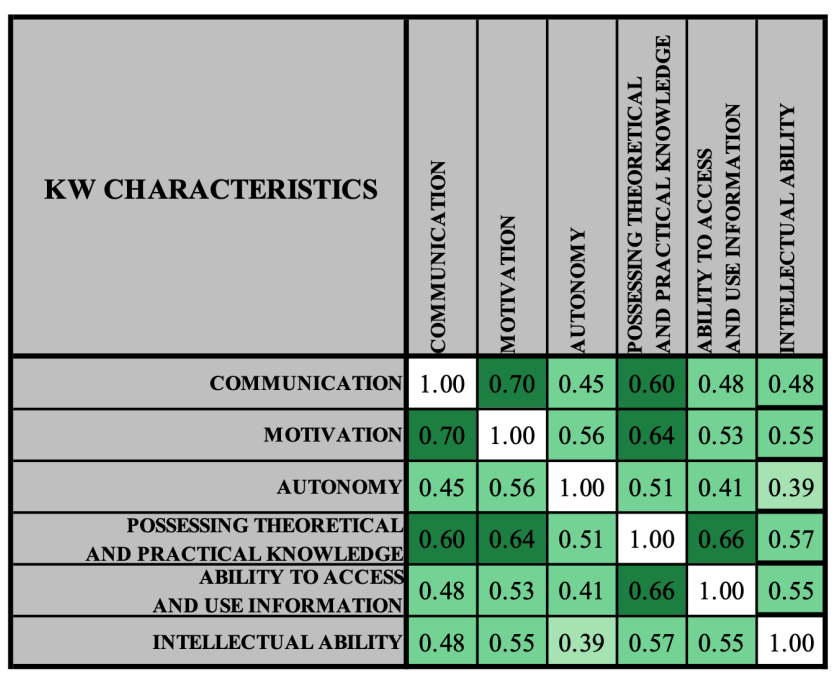

Fig. 3 Correlations among the variables

Knowledge becomes more important than assets over time, and for this reason, the concept of $\mathrm{KW}$ emerges as a subject that should be carefully considered. Construction companies especially should be aware of the values that they have to provide an advantage against their competitors because the construction sector is a competitive environment in both labour and knowledge. In this context, KWs are inevitably evaluated in parallel to their effort and skills in producing and using knowledge in the construction sector. Thus, preserving knowledge is preserving the source of knowledge that is identified as a $\mathrm{KW}$ in this research.

In the survey set up using the 5-point Likert scale, the general average of the answers of the sections related to the characteristics of KWs was accepted as the lower limit and compared with the averages of the participants. If the participant's average is above the average, they are identified as a potential KW. Thus, approximately $18 \%$ of the participants were identified as a KW as a result of this survey. The survey results are promising given the dynamics of the information age as one in five architects/engineers working in the construction sector is above average according to the results. The concept of the KW covers not only the relationship with the information but also the characteristics that determine the value of the employees such as self-sacrifice, diligence, awareness of responsibility or problem-solving ability. Given the results of this survey, the potential for employing KWs in the construction sector is remarkable.

Correlations between the answers of the participants under the headings of communication, motivation, autonomy, possessing theoretical and practical knowledge, ability to access and use information, and intellectual ability, which form the parts of the survey, were also evaluated as follows.

\subsection{The findings of KWs characteristics}

In Subsection 4.2, the responses to the KW identification survey of architects and engineers working in the Turkish construction industry were evaluated.

\subsubsection{Communication}

The analysis of the results based on the number of responses to the "communication" section is concluded in Fig. 4. The most common reply (75\%) among the communication questions is "I do not hesitate to answer the questions of my colleagues". Following this, "I share my knowledge with my colleagues" takes second place, with which $68 \%$ of the participants strongly agree. The high number of participants who strongly agree in these two statements confirms each other. Nevertheless, it is notable that the participants who attach importance to knowledge and experience sharing, have a low satisfaction rate with in-house communication in the company where they work. It is assumed that the sharing of information increases in parallel to the increase in effort 


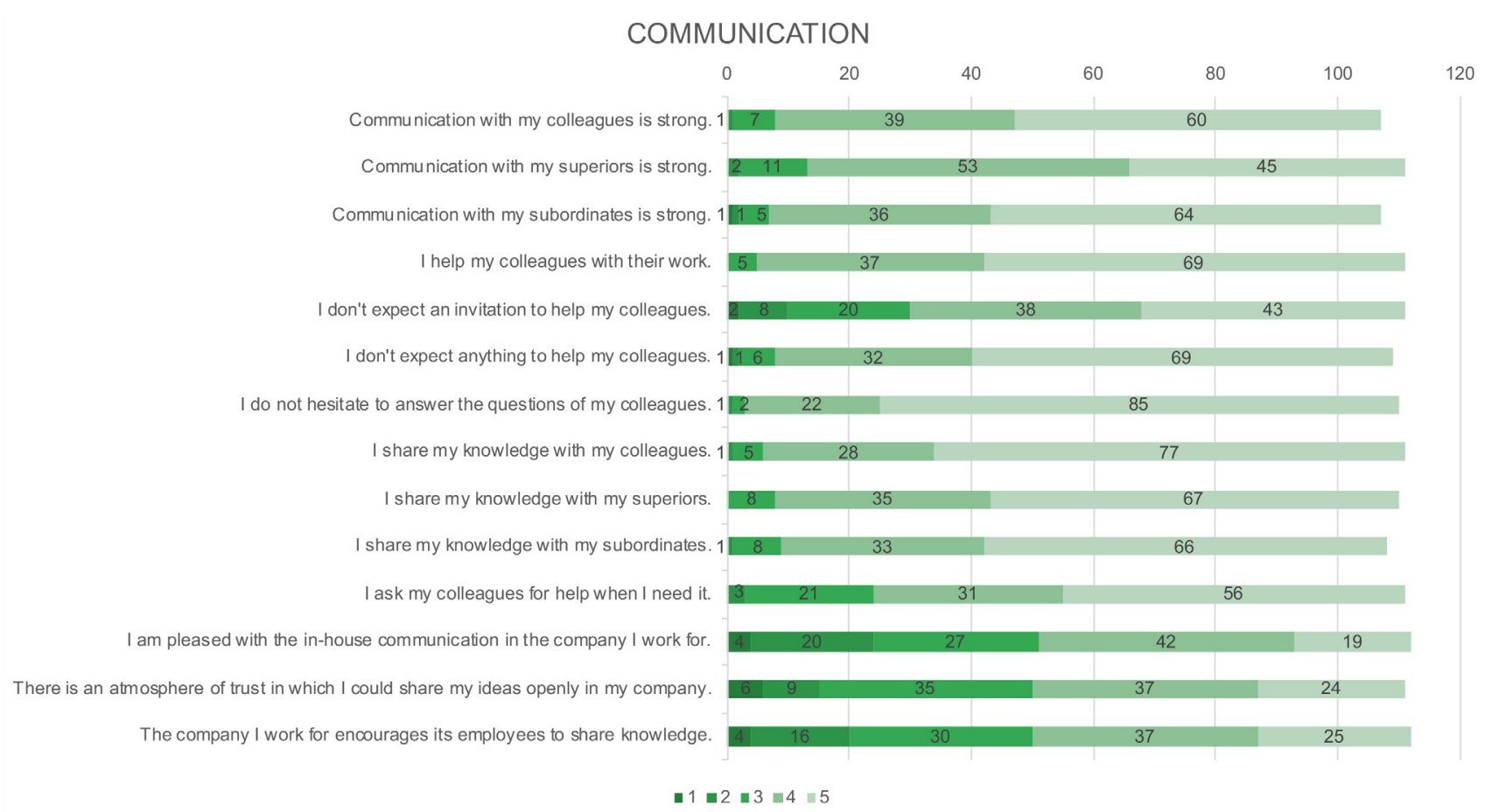

Fig. 4 The number of responses of the "communication" section in the survey

and motivation to strengthen the in-house communication in construction companies.

When the relation between "I am pleased with the in-house communication in the company I work for" and "The company I work for encourages its employees to share knowledge" is examined, there is a positive, strong and statistically significant correlation between the variables $(r=0.72$; $p<0.001$ ). Employees who are satisfied with the level of communication in the company also believe that the company encourages its employees to share information. In this context, it is possible to say that the employees do not distinguish between communication and information sharing.

The correlation between "Communication with my colleagues is strong" and "I help my colleagues with their work" is also examined. There is a positive, moderate and statistically significant correlation between the variables $(r=0.57$; $p<0.001)$. It is clear that the participants do not limit communication to "speak", but also give importance to "help". There is also a positive, moderate and statistically significant correlation between the variables $(r=0.47 ; p<0.001)$ "Communication with my colleagues is strong" and "I do not hesitate to answer the questions of my colleagues". These relationships between variables confirm each other and emphasise that individuals with effective communication are also open to help colleagues. It is possible to say that friendship in the professional business environment is not confused with business practices. However, it should be argued that the understanding of professionalism in the current business environment should be reconsidered following the fundamental dynamics of the information age. The professionalism is to prioritise sharing in an environment where access to information is easier than ever before. In this context, the $\mathrm{KW}$ is expected to expand the range of communication practices, and this correlation is indicative of the fulfilment of this expectation.

There is also a positive, moderate and statistically significant correlation between the variables $(r=0.40$; $p<0.001$ ); which are "Communication with my colleagues is strong" and "I do not expect an invitation to help my colleagues". The answers from the "I do not expect an invitation to help my colleagues" statement was considered as important in terms of demonstrating the participant's mentality regarding business ethics. It could be said that there is a significant difference in the mentality between helping a colleague without waiting for an invitation and giving support by waiting for a request for assistance. In this context, it could be interpreted that the participants who think their communication is strong, also do not expect invitations to help their colleagues. Thus, they have the potential to be KWs, and they keep the total work efficiency and team success ahead of individual success.

Another positive, moderate and statistically significant correlation between the variables $(r=0.44 ; p<0.001)$ is concluded from "Communication with my colleagues is 
strong" and "I do not expect anything from helping my colleagues". This correlation is considered a significant finding and expresses that the participants did not consider bilateral relations as transactions. A KW is primarily expected to be active in a way that ensures that things work. In this context, the expectation of help from KWs in problematic situations outside their responsibility and their contribution to solutions are expected to turn into ordinary behaviour in their professional business environment.

\subsubsection{Motivation}

The analysis of the results based on the number of responses for the "motivation" section is concluded in Fig. 5. The most common reply (73 \%) among the motivation questions was "The quality of the results I achieve in my work affects my motivation". It is a significant result because the expectations from KWs are mostly related to the quality of their work.

The most interesting result is from the answers to "Problems in my private life do not negatively affect my motivation in my job". Since it is expected that KWs can distinguish their private life from their professional life, only $15 \%$ of the participants' answers expressing that the problems do not affect them was found interesting.

The relationship between "The quality of my interaction with my colleagues affects my motivation" and "Working in harmony with my team motivates me" is examined. There is a strong, positive and statistically significant correlation between the variables $(r=0.72$; $p<0.001)$. As the quality of interaction also creates a harmonious working atmosphere, this relationship is expected to be strong. There is also a weak, positive and statistically significant correlation between "Working in harmony with my superiors motivates me" and "Clear and understandable instructions from my superiors help me to do my job better" $(r=0.25 ; p=0.008)$.

The relationship between "It motivates me to identify myself with the product/service that I produce/completed" and "The quality of the results I achieve in my work affects my motivation" is also examined. There is a moderate, positive and statistically significant correlation between the variables $(r=0.56 ; p<0.001)$. KWs' desire to define themselves in the light of their work output coincides with the fact that they are motivated by the results of their works. In practice, KWs complete their job at a certain quality level and give important clues about their business ethics and dedication as the guarantor of their work.

There is a moderate, positive and statistically significant correlation between "The balance between responsibility and authority affects my motivation" and "It motivates me to have independence while working on a task" ( $r=0.45$; $p<0.001)$. KWs, who demand a balance between their responsibilities and authority, are expected to be motivated by their level of autonomy while doing their job. Having free spaces to work and develop increases the motivation of KWs and help them realise their actions and assessments.

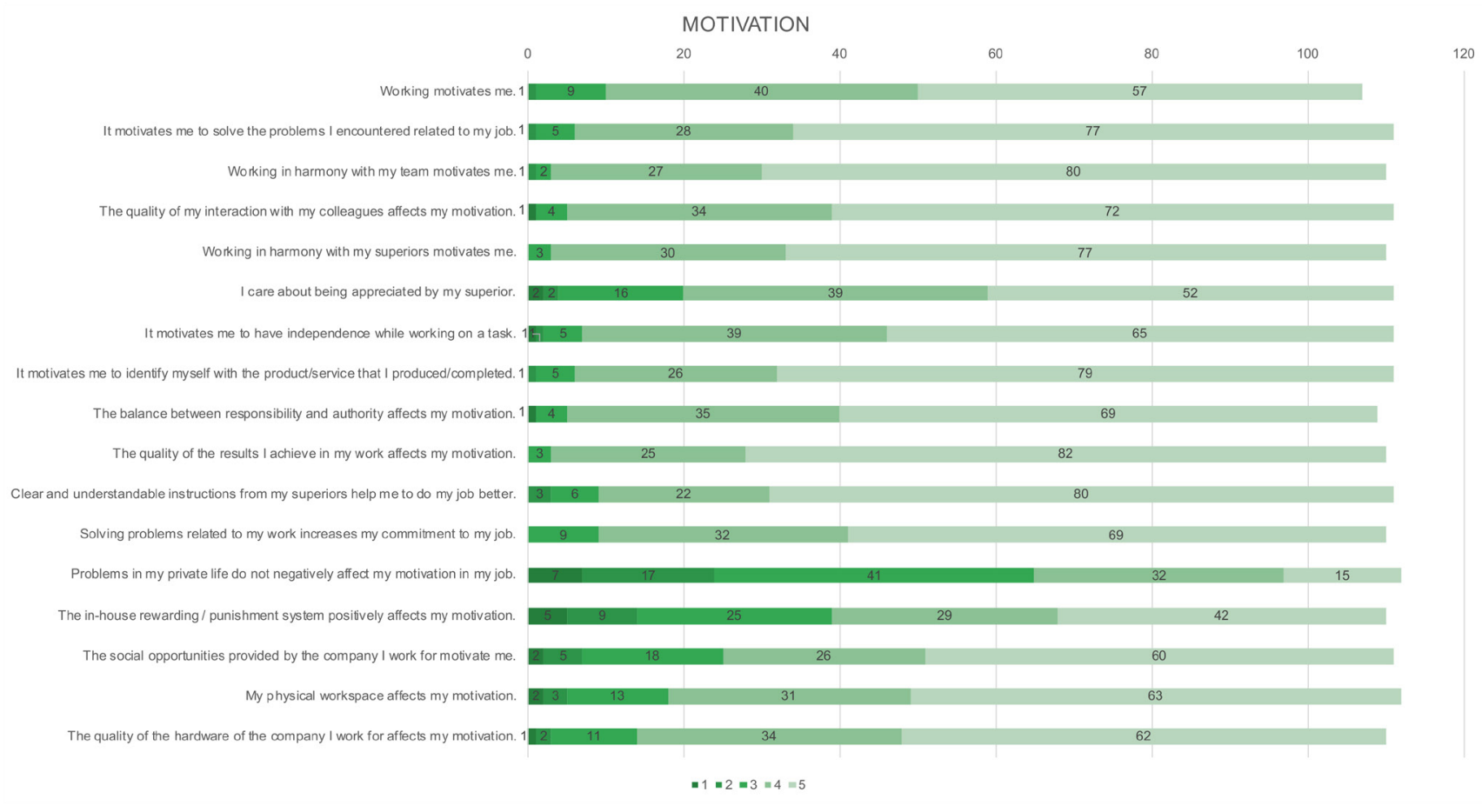

Fig. 5 The number of responses of the "motivation" section in the survey 
There is a moderate, positive and statistically significant correlation between "The social opportunities provided by the company I work for motivate me" and "My physical workspace affects my motivation" ( $r=0.47$; $p<0.001)$. KWs doing their job well have the right to think they deserve better. Therefore, it is an expected result that the motivation of KWs benefiting from the financial and moral opportunities of the company will increase.

\subsubsection{Autonomy}

The analysis of the results based on the number of responses to the "autonomy" section is concluded in Fig. 6. The most common reply (72\%) among autonomy questions was "I care about completing my work within the given time". Following this, "I take responsibility for the decisions I take about my work" in second place includes $70 \%$ of the participants.

There is a moderate, positive and statistically significant correlation between "I decide how to do my job" and "I decide when to do my job" ( $r=0.59 ; p<0.001)$. It is noteworthy that there are employees believing that they have the freedom to decide how and when to do their job in construction where all the activities are directly or indirectly interconnected. This correlation raises interest in the existence of unusual organisational structures in some companies where the survey was conducted. Suggesting it is necessary to focus on how employees control their work and responsibilities.

There is a weak, positive and statistically significant correlation between "I decide how to do my job" and "I take responsibility for the decisions I take about my work" ( $r=0.25 ; p=0.008)$. This correlation is important for the employees who claim independence to stand behind the decisions they make regarding their jobs. The responsibility of the KW should be at a high level. For this reason, they are expected to be sure of their work.

There is another weak, positive and statistically significant correlation between "I take responsibility for the decisions I take about my work" and "I do not hesitate to disagree with my superior in decisions I take about my work" $(r=0.23 ; p=0.015)$. Remarkably, employees who tend to defend their decisions do not hesitate to have conflicts with their manager when necessary in terms of showing how confident they are in what they are doing.

\subsubsection{Possessing theoretical and practical knowledge}

The analysis of the results based on the number of responses for the "possessing theoretical and practical knowledge" section is concluded in Fig. 7. The most common reply (61 \%) among the section questions in Subsubsection 4.2.4 was "I believe that I will use the knowledge and experience I have gained within the company in other companies in the sector". Following this, "I need to share my knowledge with my colleagues" takes second place, with $55 \%$ of the participants strongly agreeing.

There is a moderate, positive and statistically significant correlation between "I have an active role in in-house knowledge exchange and transfer activities" and "I have knowledge that is important for my job description and cooperation in the company" ( $r=0.44 ; p<0.001)$. It is considered as an important result because the employee having valuable knowledge in the company also takes an active role in the movement of this knowledge.

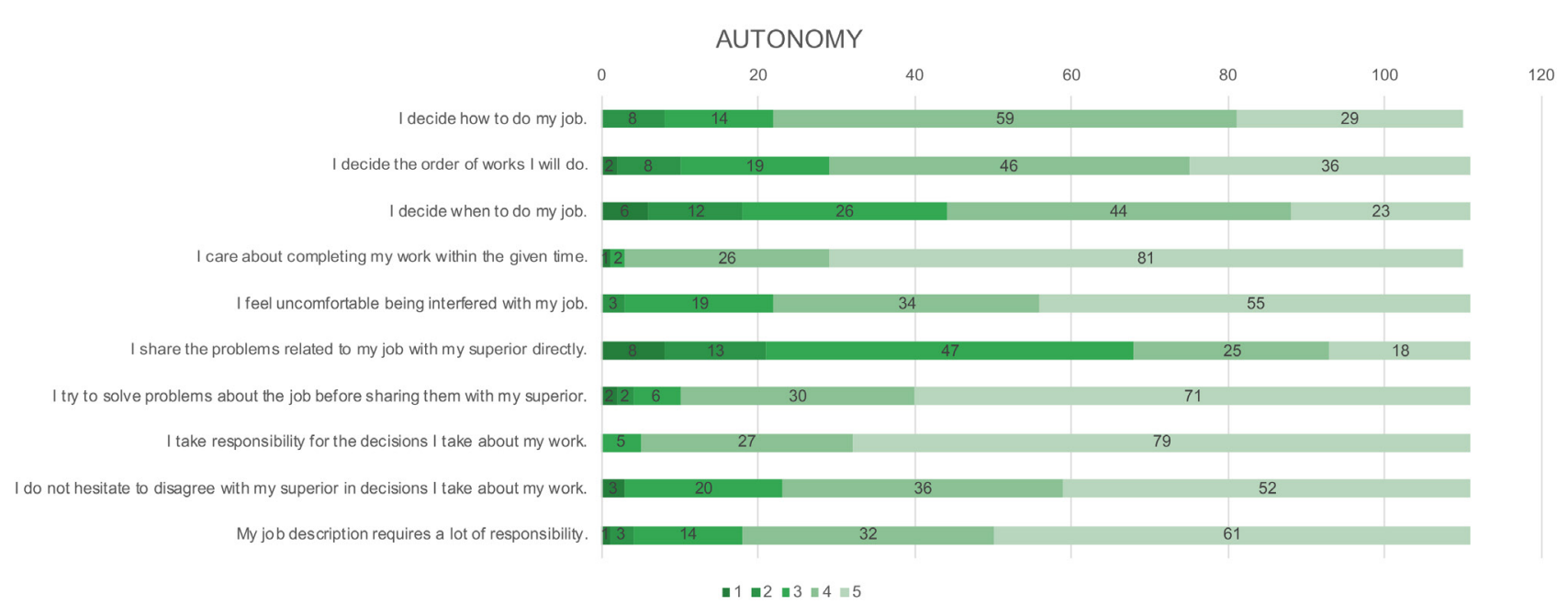

Fig. 6 The number of responses of the "autonomy" section in the survey 


\section{POSSESSING THEORETICAL AND PRACTICAL KNOWLEDGE}

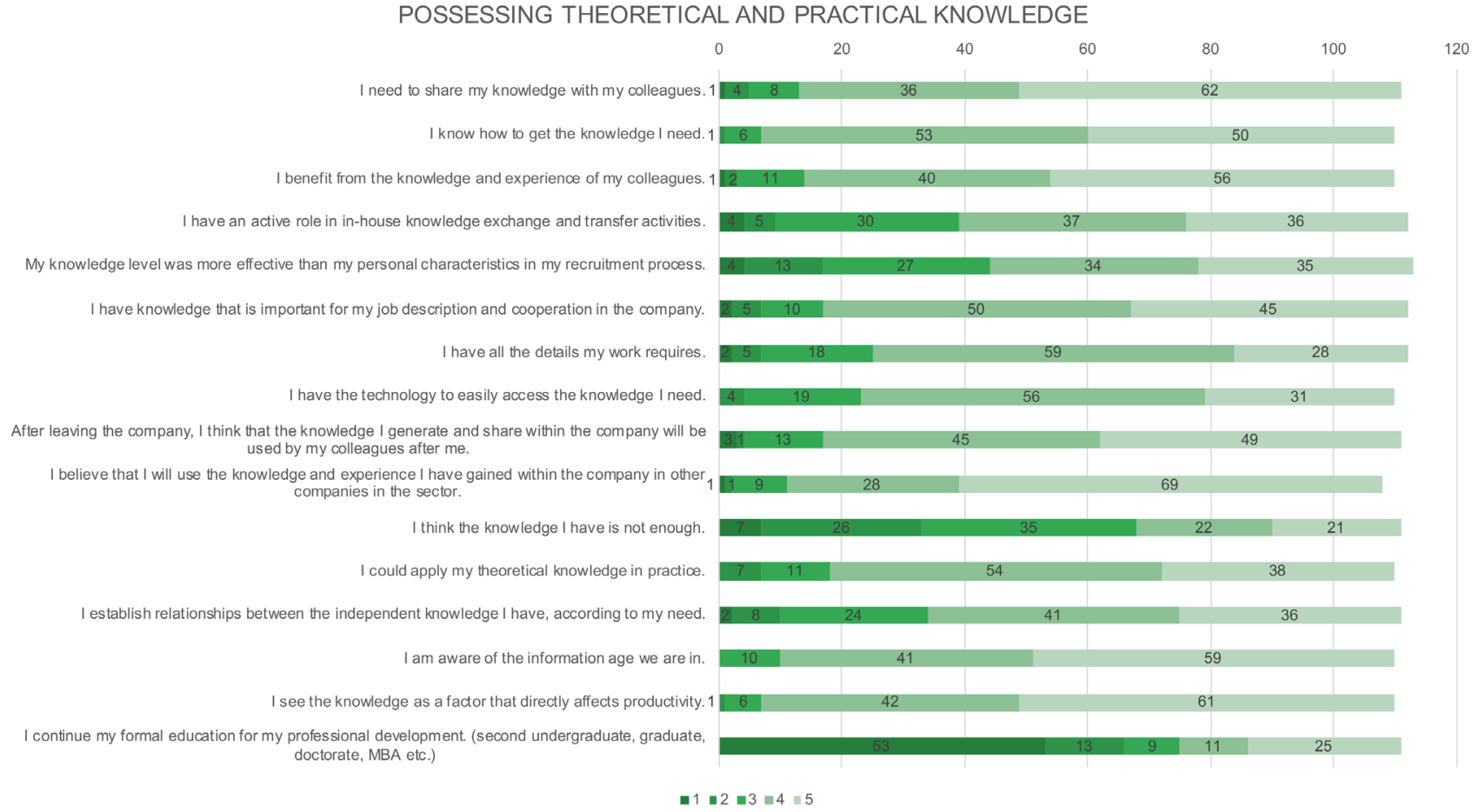

Fig. 7 The number of responses of the "possessing theoretical and practical knowledge" section in the survey

There is a moderate, positive and statistically significant correlation between "I need to share my knowledge with my colleagues" and "I benefit from the knowledge and experience of my colleagues" $(r=0.47 ; p<0.001)$. This correlation shows that employees contribute to the knowledge exchange activity when it is necessary.

There is a moderate, positive and statistically significant correlation between "I could apply my theoretical knowledge in practice" and "I establish relationships between the independent knowledge I have, according to my need" $(r=0.55 ; p<0.001)$. It is especially important that the employee can transfer theoretical knowledge into practice. Similarly, KWs are expected to correlate different knowledge end experiences when it is necessary. They should also produce new knowledge through different knowledge interactions.

There is a weak, positive and statistically significant correlation between "After leaving the company, I think that the knowledge I generate and share within the company will be used by my colleagues after me" and "I believe that I will use the knowledge and experience I have gained within the company in other companies in the sector" $(r=0.35 ; p<0.001)$. The employees, who think that the knowledge they produce in the company can be used after leaving the company, also think that they can use the knowledge they have in other companies in the sector. This shows that knowledge depends on or belongs to the employee who produces it, not the firm. The knowledge possessed by the KW should be able to be utilised independently from the time and place.

\subsubsection{Ability to access and use information}

The analysis of the results based on the number of responses for the "ability to access and use information" section is concluded in Fig. 8. The most common reply (58 \%) among information questions was "I'm open to new information". Following this, "I'm willing to get new information" takes second place, of which $56 \%$ of the participants strongly agree.

There is a strong, positive and statistically significant correlation between "I know how to get the information" and "I know where to start looking for the information I need" $(r=0.72 ; p<0.001)$. The presence of the employees who know where to find the information they need is vital to ensure an efficient internal working environment. It could be said that the employees who know how to reach the correct information have the potential to become a KW.

There is a moderate, positive and statistically significant correlation between "I use the information my colleagues produce/have" and "I get support from my social circle to access the information I need" ( $r=0.54 ; p<0.001)$. It is considered as a remarkable result for employees to receive 


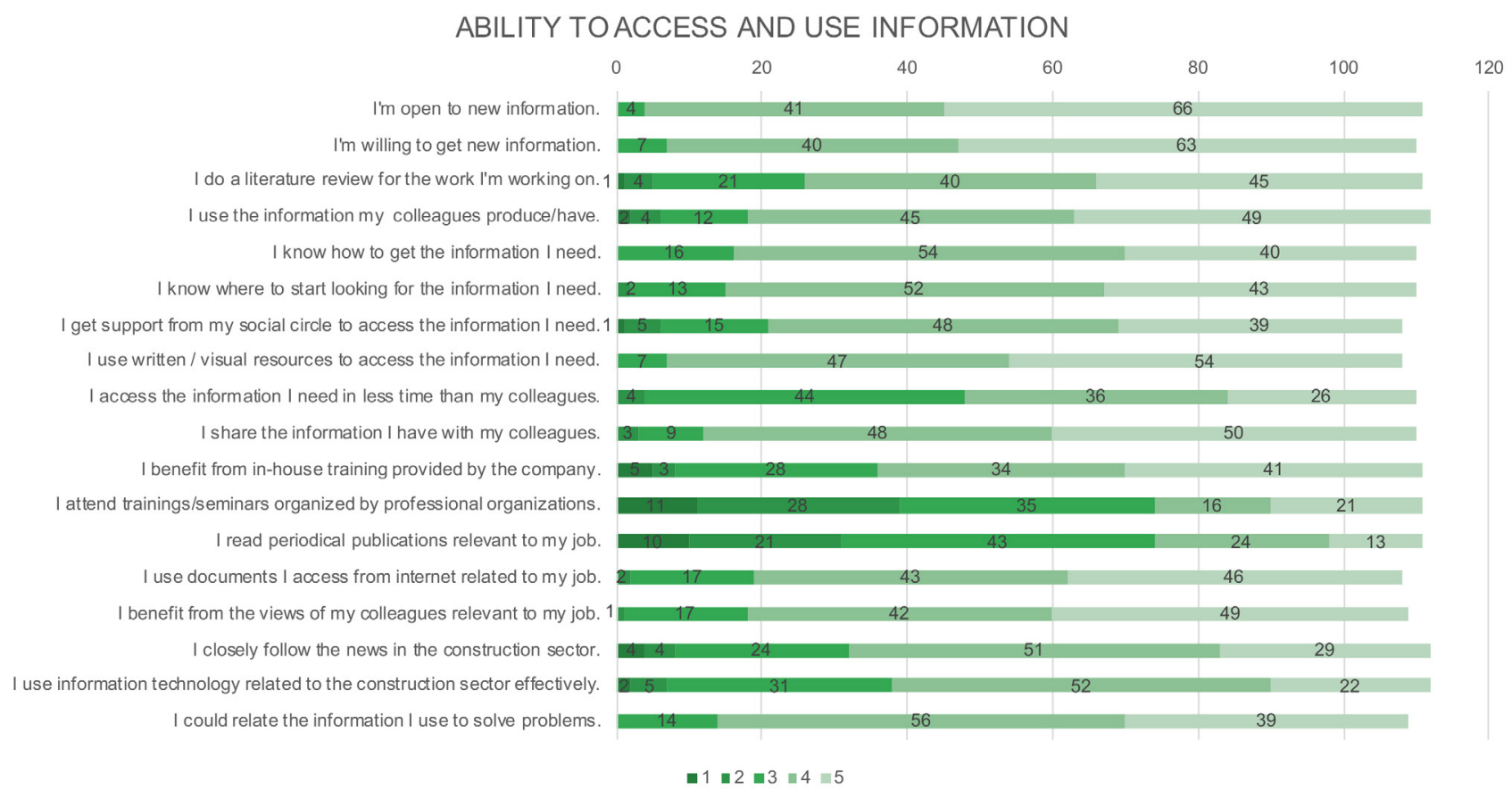

Fig. 8 The number of responses of the "ability to access and use information" section in the survey

support from their relatives to access the information they need. Contrary to the competitive and uncommunicative approach, the sharing attitude has been evaluated as positive.

There is a weak, positive and statistically significant correlation between "I access the information I need in less time than my colleagues" and "I share the information I have with my colleagues" $(r=0.38 ; p<0.001)$. The tendency of employees to reach the information in a shorter time than their colleagues is not by using their ability to work quickly to gain a competitive advantage.

There is a moderate, positive and statistically significant correlation between "I read periodical publications relevant to my work" and "I use documents I access from internet related to my job" ( $r=0.40 ; p<0.001)$. This correlation is important in terms of registering the presence of staff who evaluate different alternatives for self-improvement to do their job better. In a period when digital tools are so dominant in daily life, the positive answers about periodicals are quite remarkable. This approach towards printed publications is pleasing and promising.

There is a moderate, positive and statistically significant correlation between "I benefit from in-house training provided by the company" and "I attend training/seminars organised by professional organisations" $(r=0.51 ; p<0.001)$. The participation in the activities organised for the personal and professional development of staff shows that they use the opportunities they have to reach the information they need.

\subsubsection{Intellectual ability}

The analysis of the results based on the number of responses for the "intellectual ability" section is concluded in Fig. 9. The most common reply (55\%) among information questions was, "When my solution doesn't work, I try to find out the reason". Following this, "I'm objective and sensible" and "I try to solve problems quickly" both take second place, of which $51 \%$ of participants strongly agree.

There is a weak, positive and statistically significant correlation between "I produce effective solutions to the problems I face in a short time while doing my job" and "I try to solve problems without losing time with details" $(r=0.37 ; p<0.001)$. The construction is a sector where production occurs with limited resources, and any wastage should be seen as a loss. For this reason, it is imperative to produce solutions quickly. Losing the big picture by drowning in details is a common mistake in the construction industry. Trying to identify the responsible person instead of developing a solution in the face of a problem is one of the most common examples. However, the number of properly solved problems for a $\mathrm{KW}$ is an extra source of motivation. For this reason, eliminating problems as fast as possible is the opportunity to solve new ones for KWs. This correlation is valuable in terms of revealing a KW's approach in producing effective solutions in a short time without losing time with details. 


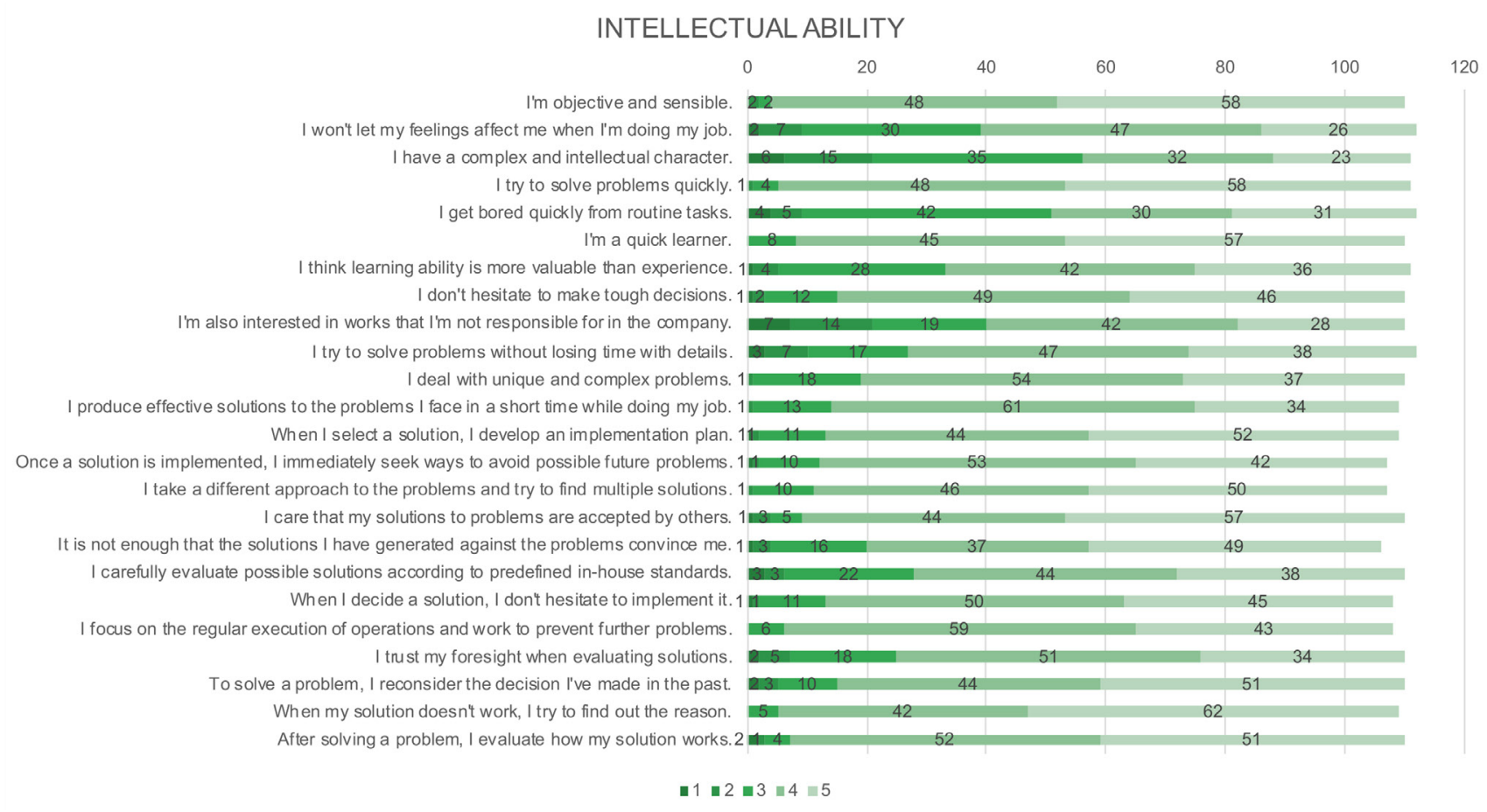

Fig. 9 The number of responses of the "intellectual ability" section in the survey

There is a strong, positive and statistically significant correlation between "When my solution doesn't work, I try to find out the reason" and "After solving a problem, I evaluate how my solution works" ( $r=0.72 ; p<0.001)$. The tendency of the employees to evaluate their solutions regardless of the result is significant. An employee determined as a potential $\mathrm{KW}$ is expected to be able to eliminate the negative consequences of a solution to a problem. Similarly, KWs need to better prepare themselves for the next problem by thinking about the previous problems they have solved.

There is a moderate, positive and statistically significant correlation between "I try to solve problems quickly" and "I produce effective solutions to the problems I face in a short time while doing my job" ( $r=0.47 ; p<0.001)$. This correlation is important as it reveals the practical thinking skills among employees. This feature is vital for KWs.

There is a moderate, positive and statistically significant correlation between "I am a quick learner" and "I think learning ability is more valuable than experience" ( $r=0.45$; $p<0.001)$. It is evaluated as a consistent result because employees who think the learning ability is more valuable than the experience also learn quickly.

There is a weak, positive and statistically significant correlation between "I have a complex and intellectual character" and "I think learning ability is more valuable than experience" ( $r=0.29 ; p=0.003)$. It should be noted that learning ability should be emphasised in the construction sector, as there is no shortage of experiential learning. Employment age and long periods of employment should not be the only prerequisite for seniority or having better working conditions. It is possible to say that this difference of opinion is the basis of the conflict between generation $\mathrm{X}$ and generation $\mathrm{Y}$ in the construction sector. It can be considered reasonable to find self-developed, intellectual employees who think learning ability is more valuable than the experience.

\section{Conclusion and recommendations}

Knowledge is becoming increasingly more important than assets; thus, the concept of KW emerges as a subject that should be given considerable and considered attention. Construction companies should be especially aware of the value that they have developed to provide an advantage over their competitors, as the construction sector is a competitive environment in both labour and knowledge. In this context, inevitably, KWs, who can produce, use, transfer and save knowledge are consistently evaluated with their potentials in the construction sector. The most practical and healthiest way to preserve "knowledge" is to preserve the "source of knowledge". Thus, it is crucial to identify the "sources" accurately.

This study aims to determine the KWs in large-scale contractors in the Turkish construction sector through a survey based on specified characteristics of KWs. 
The results of this survey reveal the presence of KWs in the Turkish construction sector.

Considering the construction projects conducted with limited sources and the rigid and bulky organisation structures of the present construction companies, the determination of the KWs who believe that they are not in the position that they deserve in the hierarchy is critical. Thus, this study is considered a crucial beginning for the evaluation of KWs according to their capabilities and potential specific to the construction sector in Turkey.

This study proposes a survey-based model for the identification of KWs in the Turkish construction sector. This survey reveals the presence of KWs in large-scale construction companies. Demographic data obtained in the survey indicated the remarkable results that female

\section{References}

Antikainen, R., Lönnqvist, A. (2005) "Knowledge Work Productivity Assessment", In: 3rd Conference on Performance Measurement and Management Control, Nice, France, pp. 1-18.

Brace, I. (2004) "Questionnaire Design: How to Plan, Structure, and Write Survey Material for Effective Market Research", Kogan Page, London, UK.

Carlbring, P., Brunt, S., Bohman, S., Austin, D., Richards, J., Öst, L. G., Andersson, G. (2007) "Internet vs. paper and pencil administration of questionnaires commonly used in panic/agoraphobia research", Computers in Human Behavior, 23(3), pp. 1421-1434. https://doi.org/10.1016/j.chb.2005.05.002

Carrillo, P. M., Anumba, C. J., Kamara, J. M. (2000) "Knowledge Management Strategy for Construction: Key I.T. and Contextual Issues", In: Proceedings of the International Conference on Construction Information Technology (CIT2000), Reykjavik, Iceland, pp. 155-165.

Carty, G. J. (1995) "Construction", Journal of Construction Engineering and Management, 121(3), pp. 319-328.

Cochran, G. R., Ferrari, T. M. (2009) "Preparing Youth for the 21st Century Knowledge Economy: Youth Programs and Workforce Preparation", Afterschool Matters, 8, pp. 11-25.

Cronbach, L. J. (1951) "Coefficient alpha and the internal structure of tests", Psychometrika, 16(3), pp. 297-334. https://doi.org/10.1007/BF02310555

Dainty, A., Moore, M., Murray, M. (2006) "Communication in Construction: Theory and Practice", Routledge, London, UK. https://doi.org/10.4324/9780203358641

Davenport, T. H. (2005) "Thinking for A Living: How to Get Better Performances and Results From Knowledge Workers", Harvard Business School Press, Boston, MA, USA.

Davenport, T. H. (2007) "Information Technologies for Knowledge Management", In: Ichijo, K. Nonaka, I. (eds.) Knowledge Creation and Management: New Challenges for Managers, Cambridge University Press, New York, NY, USA, pp. 97-109. employees, employees from generation $\mathrm{Y}$, employees with $\mathrm{PhD}$ degrees and architects meet the requirements of being a KW more than others. Considering the methodology and the results in the "Results and Discussion" section, this study provides a basis for the awareness of KWs in the construction sector. It enables the evaluation of KWs according to their potential and skills to increase efficiency and create a dynamic organisational structure, which can be updated according to the changing conditions in the sector.

\section{Acknowledgement}

This work was supported by the Scientific Research Projects Coordination Unit of Istanbul Technical University, Project Number: 42396.

den Hertog, P., Bilderbeek, R. (1998) "Technology-Based KnowledgeIntensive Business Services in the Netherlands: Their Significance as a Driving Force behind Knowledge-Driven Innovation", Vierteljahrshefte zur Wirtschaftsforschung, 67(2), pp. 126-138. [online] Available at: https://www.econstor.eu/ handle/10419/141202 [Accessed: 06 February 2020]

Drucker, P. F. (1954) "The Practice of Management", Harper \& Row, New York, NY, USA.

Drucker, P. F. (1959) "Landmarks of Tomorrow", Harper \& Row, New York, NY, USA.

Drucker, P. F. (1967) "The Effective Executive", Harper \& Row, New York, NY, USA.

Drucker, P. F. (1985) "Innovation and Entrepreneurship: Practice and Principles", Heinemann, London, UK.

Drucker, P. F. (1999a) "Knowledge-Worker Productivity: The Biggest Challenge", California Management Review, 41(2), pp. 79-94. https://doi.org/10.2307/41165987

Drucker, P. F. (1999b) "Management Challenges for The 21st Century", Transaction Publishers, Piscataway, NJ, USA.

Drucker, P. F. (2005) "Managing oneself", Harvard Business Review, Brighton, MA, USA.

Eisenhardt, K. M., Santos, F. M. (2006) "Chapter 7: Knowledge-Based View: A New Theory of Strategy?", In: Pettigrew, A., Thomas, H., Whittington, R. (eds.) Handbook of Strategy and Management, SAGE Publications Ltd, London, UK, pp. 139-164. https://doi.org/10.4135/9781848608313.n7

Fisher, R. A. (1925) "Statistical Methods for Research Workers", Oliver and Boyd, Edinburgh, UK.

Giritli, H., Topçu Oraz, G., Kaya Yılmaz, S. (2010) "Behavioral Aspects of Communication in Construction", In: Construction, Building and Real Estate Research Conference of the Royal Institution of Chartered Surveyors (COBRA 2010), Paris, France. [online] Available at: https:/www.researchgate.net/ publication/324756980_Behavioral_aspects_of_communication_ in_construction [Accessed: 06 February 2020] 
Green, S. D., Newcombe, R., Fernie, S., Weller, S. (2004) "Learning across business sectors: Aspects of human resource management in aerospace and construction", In: Kalidindi, S. N., Varghese, K. (eds.) Project Procurement for Infrastructure Construction, Narosa Publishing House, New Delhi, India, pp. 218-226.

Issa, R. R. A., Haddad, J. (2008) "Perceptions of the impacts of organisational culture and information technology on knowledge sharing in construction", Construction Innovation, 8(3), pp. 182-201. https://doi.org/10.1108/14714170810888958

Kamara, J. M., Anumba, C. J., Carrillo, P. M., Bouchlaghem, N. D. (2003) "Conceptual framework for live capture and reuse of project knowledge", In: International Conference on Information Technology for Construction, Waiheke Island, New Zealand, pp. 178-186.

Kivrak, S., Arslan, G., Dikmen, I., Birgonul, M. T. (2008) "Capturing Knowledge in Construction Projects: Knowledge Platform for Contractors", Journal of Management in Engineering, 24(2), pp. 87-95. https://doi.org/10.1061/(ASCE)0742-597X(2008)24:2(87)

Kululanga, G. K., McCaffer, R. (2001) "Measuring knowledge management for construction organisations", Engineering, Construction and Architectural Management, 8(5/6), pp. 346-354. https://doi.org/10.1108/eb021195

Loosemore, M., Dainty, A., Lingard, H. (2003) "Human Resource Management in Construction Projects: Strategic and Operational Approaches", Routledge, London, UK. https://doi.org/10.4324/9780203417881

Machlup, F. (1962) "The Production and Distribution of Knowledge in the United States", Princeton University Press, Princeton, NJ, USA.

McGovern, G. (1999) "The Caring Economy: Business Principles for The New Digital Age", Blackhall, Dublin, Ireland.

Mohanta, G. C., Kannan, V., Thooyamani, K. P. (2006) "Strategies For Improving Productivity Of Knowledge workers-An overview", In: Pulla, V., Montgomery, C. (eds.) Strength Based Strategies 2006, Brisbane Institute of Strengths Based Practice, Coopers Plains, Australia, pp. 77-84.

Morgeson, F. P., Humphrey, S. E. (2006) "The Work Design Questionnaire (WDQ): Developing and validating a comprehensive measure for assessing job design and the nature of work.", Journal of Applied Psychology, 91(6), pp. 1321-1339. https://doi.org/10.1037/0021-9010.91.6.1321

Ökten, B. B. (2016) "Türk İnşaat Sektöründe Küçük ve Orta Ölçekli Firmalarda Bilgi Yönetimi" (Knowledge Management in Small and Medium Sized Firms in Turkish Construction Sector), PhD Theses, Ylldiz Technical University. (in Turkish) https://doi.org/10.13140/RG.2.2.14640.15366

Ozorhon, B., Karatas, C. G., Demirkesen, S. (2014) "A Web-based Database System for Managing Construction Project Knowledge", Procedia - Social and Behavioral Sciences, 119, pp. 377-386. https://doi.org/10.1016/j.sbspro.2014.03.043
Pathirage, C. P., Amaratunga, R. D. G., Haigh, R. P. (2005) "Managing the construction worker in a knowledge environment", In: Proceedings of 2nd Scottish Conference for the Post Graduate Researchers of the Built and Natural Environment, Glasgow, UK, pp. 757-768.

Reboul, C., Horel, G., Kurtousova, Z., Lanthier, T., Mutschlechner, E., Pastia, D., Slota, J. (2006) "Managing Knowledge Workers: The KWP Matrix", In: Conference Proceedings MOMAN, Praha, Czech Republic, pp. 261-275.

Rezgui, Y. (2001) "Review of information and the state of the art of knowledge management practices in the construction industry", The Knowledge Engineering Review, 16(3), pp. 241-254. https://doi.org/10.1017/S026988890100008X

Schröpfer, V. L. M., Tah, J., Kurul, E. (2017) "Mapping the knowledge flow in sustainable construction project teams using social network analysis", Engineering, Construction and Architectural Management, 24(2), pp. 229-259. https://doi.org/10.1108/ECAM-08-2015-0124

Sheehan, T., Poole, D., Lyttle, I., Egbu, C. O. (2005) "Strategies and Business Case for Knowledge Management", In: Anumba, C. J., Egbu, C. O., Carrillo, P. M. (eds.) Knowledge Management in Construction, Blackwell Publishing, Oxford, UK, pp. 50-64. https://doi.org/10.1002/9780470759554.ch4

The Boston Consulting Group (2016) "Shaping the Future of Construction: A Breakthrough in Mindset and Technology", World Economic Forum, Colgony, Switzerland, Rep. REF 220416. [online] Available at: http://www3.weforum.org/docs/WEF_Shaping_the_Future_ of_Construction_full_report__.pdf [Accessed: 16 March 2020]

Webb, S. P. (1998) "Knowledge Management: Linchpin of Change", Routledge, London, UK. https://doi.org/10.4324/9781351227223

Wong, P. S. S. (2012) "Drucker's Knowledge-worker Productivity Theory: A Practitioner's Approach to Integrating Organisational Work Processes with Drucker's Six Major Factors Determining Knowledge-Worker Productivity", PhD Theses, Southern Cross University.

Yang, J., Fang, L. L., Ling, W. Q. (2002) "Find the Real Meaning of Knowledge Workers", Chinese Talents Magazine, 8, pp. 30-31.

Zhan, H., Tang, T., Zhang, Y. (2013) "The Research on Characteristics of Knowledge Workers and Their Motivating Factors: A Review and Comparison Study", American Journal of Industrial and Business Management, 3(6), pp. 557-564. https://doi.org/10.4236/ajibm.2013.36064 